\title{
PROPOSTA DE UM MODELO PARA AVALIAÇÃO DAS CARACTERÍSTICAS INOVADORAS DOS PROJETOS SUBMETIDOS AO PROGRAMA JURO ZERO
}

\section{PROPOSAL OF A MODEL FOR EVALUATION OF INNOVATIVE FEATURES OF PROJECTS SUBMITTED TO ZERO INTEREST PROGRAM}

\author{
Diane Rossi Maximiano Reina ${ }^{1}$; Sandra Ensslin ${ }^{2}$; Leonardo Ensslin ${ }^{3}$; Donizete Reina ${ }^{4}$ \\ ${ }^{1}$ Universidade Federal de Santa Catarina - UFSC - Florianópolis - Brasil \\ dianereina@hotmail.com \\ ${ }^{2}$ Universidade Federal de Santa Catarina - UFSC - Florianópolis - Brasil \\ sensslin@gmail.com \\ ${ }^{3}$ Universidade Federal de Santa Catarina - UFSC - Florianópolis - Brasil \\ leonardoensslin@gmail.com \\ ${ }^{4}$ Universidade Federal de Santa Catarina - UFSC - Florianópolis - Brasil \\ dreina2@hotmail.com
}

\begin{abstract}
Resumo
O presente artigo tem como objetivo construir um modelo de avaliação das características inovadoras das propostas dos projetos submetidos ao programa juro zero, de forma a auxiliar na gestão do processo de qualificação das propostas submetidas pelas MPEIs de Santa Catarina ao PJZ, utilizando-se da Metodologia Multicritério de Apoio à decisão Construtivista (MCDA-C). A pesquisa caracteriza-se como um estudo de caso, para a coleta dos dados utiliza a técnica de entrevista e análise documental com abordagem qualitativa dos dados na fase de estruturação $e$ quantitativa na fase de avaliação. $O$ instrumento de intervenção utilizado para construir o modelo foi a Metodologia Multicritério de Apoio à Decisão Construtivista (MCDA-C). Os resultados encontrados evidenciam que a partir do conhecimento gerado foi possível a construção de um modelo que possibilitou ao coordenador do programa: (i) identificar os 20 critérios que compõem o modelo para avaliação das características inovadoras das propostas submetidas ao PJZ; (ii) construir escalas ordinais e cardinais para cada indicador; (iii) avaliar o perfil de desempenho (status quo) de duas propostas submetidas ao programa; (iv) identificar os indicadores com desempenho comprometedor e gerar ações de aperfeiçoamento que possa melhorar o perfil de desempenho das propostas. Conclui-se que as informações geradas a partir do modelo possibilitam à coordenadora do programa visualizar o perfil de desempenho das propostas submetidas, proporcionando transparência no processo de seleção das empresas. Também permite às empresas identificar de forma específica os critérios que necessitam melhorar para que suas propostas sejam aceitas.
\end{abstract}

Palavras-chave: seleção de projetos; avaliação de desempenho; MCDA-C; inovação tecnológica. 


\section{Introdução}

Para atender às exigências do mercado em termos de qualidade, baixos custos, flexibilidade e satisfação do cliente, o sucesso das organizações depende de sua capacidade de atender a essas exigências, por meio de inovações contínuas em seus produtos, processos e serviços (SOARES et al, 2006). O estimulo às atividades inovadoras possibilita oportunidades para as empresas em termos de crescimento e expansão em novas áreas, estabelecer posições competitivas dominantes, gerando emprego, renda e desenvolvimento (PEREIRA e KRUGLIANSKA, 2006; DANNEELS e KLEINSCHMIDT 2001).

Neste contexto observa-se que a inovação tem um papel fundamental para o crescimento econômico das empresas e da sociedade em geral. No entanto, as atividades inovadoras estão associadas a elevados riscos e desafios de gestão. Em virtude dos elevados custos e da incerteza na geração de benefícios econômicos futuros intrínsecos à inovação tecnológica, as micro e pequenas empresas encontram dificuldades na busca de recursos para investir em inovações. Segundo Corder e Salles-Filho (2006) o capital necessário ao investimento em inovações pode ter várias origens: o sistema financeiro convencional com linhas de crédito especiais; o mercado de capitais; os recursos próprios; os fundos mútuos; os fundos públicos de fomento à ciência, tecnologia e informação (C\&T\&I).

No Brasil boa parte dos recursos destinados às atividades de inovação tecnológica é oriunda de recursos governamentais. Evidenciando a importância das políticas de incentivo à inovação, principalmente por meio de financiamentos para a inserção e difusão de um ambiente inovativo na economia. Dessa forma, percebe-se que o crédito é o vetor que liga o processo de invenção (desenvolvimento de pesquisas) à inovação materializada em novos produtos/processos e serviços (CORDER e SALLES-FILHO, 2006; YANOMINI e GONÇALVES, 2010).

Com o intuito de apoiar a inovação tecnológica, a Financiadora de Estudos e Projetos (FINEP), empresa pública vinculada ao Ministério da Ciência e Tecnologia (MCT), lançou, o Programa Juro Zero (PJZ). O Programa tem por objetivo promover e financiar a inovação e a pesquisa científica e tecnológica desenvolvidas por Micro e Pequenas Empresas Inovadoras (MPEIs), que representem uma inovação em seu setor de atuação. Sendo assim, o Programa Juro Zero (PJZ) visa estimular o desenvolvimento das Micro e Pequenas Empresas Inovadoras (MPEIs) brasileiras, viabilizando o acesso ao crédito pelo financiamento de longo prazo.

Para obtenção do financiamento as MPEIs passam por um processo de seleção, onde os projetos submetidos são avaliados. Como parceira do programa no estado de Santa Catarina, a Associação Catarinense das Empresas de Tecnologia (ACATE) possui a responsabilidade pela qualificação dos projetos submetidos. Sendo, portanto, a gestão do processo de seleção dos projetos 
um dos grandes desafios enfrentados pelo Programa, devido à complexidade dos projetos associada a limitações de recursos financeiros, assim como seus impactos na área econômica e social, faz com que o processo de seleção tenha elevada repercussão regional. Percebe-se então a necessidade de critérios confiáveis e transparentes que auxiliem na gestão do processo de seleção dos projetos. Assim, a presente pesquisa busca investigar: Quais são os aspectos a serem considerados em um modelo que pretende apoiar a gestão do processo de seleção de projetos inovadores?

Para responder tal questionamento, o presente artigo tem como objetivo construir um modelo de avaliação das características inovadoras das propostas dos projetos submetidos ao programa juro zero, de forma a auxiliar na gestão do processo de qualificação das propostas submetidas pelas MPEIs de Santa Catarina ao PJZ, utilizando-se da Metodologia Multicritério de Apoio à decisão Construtivista (MCDA-C). Na busca de resposta ao problema central da pesquisa, foram formulados os seguintes objetivos específicos: (i) construir entendimento da questão pela identificação dos aspectos que a Coordenadora do PJZ no estado de Santa Catarina considera necessários e suficientes para avaliação das características inovadora das empresas; (ii) construir escalas ordinais e cardinais para os aspectos identificados; (iii) integrar os aspectos via taxas de compensação, conforme a percepção da coordenadora; e (iv) ilustrar o perfil do desempenho de duas proposta submetidas ao PJZ.

Ao analisar a literatura existente sobre avaliação e seleção de projetos inovadores na base de dados Web of Science (ISI), identificou-se que embora existam estudos sobre critérios e modelos a serem utilizados no processo de avaliação e seleção de projetos (BITMAN e SHARIF, 2008; HART et al., 2003; ASTEBRO, 2004; CARBONELL, ESCUDERO e ALEMAN, 2004; LOCH et al., 2001; MAVROTAS, DIAKOULAKI e KOURENTZIS, 2009) não identificou-se estudos com o propósito de estabelecer critérios para avaliação das características inovadoras de projetos, favorecendo assim a gestão do processo de seleção de projetos inovadores.

A importância da pesquisa pode ser confirmada pelos seguintes aspectos: (i) contribuição à comunidade científica pela construção e aplicação de um modelo de Avaliação de Desempenho envolvendo a metodologia Multicritério de Apoio à Decisão Construtivista (MCDA-C) em empresas de base tecnológica; (ii) os resultados desta pesquisa auxiliarão como facilitadores no processo de gestão dos recursos destinado ao financiamento de Projetos Inovadores; e, (iii) por possibilitar transparência em relação à aplicação dos recursos públicos.

O presente estudo está organizado em cinco seções: após esta primeira seção de caráter introdutório, apresenta-se, na segunda, o referencial teórico sobre Inovação Tecnológica, Avaliação de Desempenho e seleção de projetos inovadores; na terceira seção, apresentam-se a metodologia da pesquisa e o procedimento para construção do modelo; na quarta, apresentam-se os resultados da 
pesquisa; na quinta e última seção, apresentam-se as considerações finais. Por fim, elencam-se as referências utilizadas na pesquisa.

\section{Referencial Teórico}

O eixo teórico que informa o presente estudo é explorado, em termos da revisão de literatura, na subseção a seguir.

\subsection{Inovação Tecnológica}

O termo "inovação" possui diferentes definições entre os pesquisadores, desta forma para caracterizar a inovação o Programa Juro Zero adotou a definição constante no artigo 17 da Lei n. 11.196/2005 que considera:

\footnotetext{
Inovação tecnológica como a concepção de novo produto ou processo de fabricação, bem como a agregação de novas funcionalidades ou características ao produto ou processo que impliquem melhorias incrementais e efetivo ganho de qualidade ou produtividade, resultando em maior competitividade no mercado.
}

As atividades de inovação variam de empresa para empresa. Algumas empresas desenvolvem projetos de inovação com o objetivo de desenvolver e introduzir um produto novo no mercado, enquanto outras empresas desenvolvem projetos com o objetivo de realizar aprimoramentos nos produtos já comercializados pela empresa (Manual Oslo, 1997). Dannels e Kleinschmidt (2001) categorizam os produtos em duas dimensões de inovação: inovação para a empresa que irá desenvolver o produto e inovação para o mercado. Segundo os autores os produtos novos para o mundo são novos tanto para a empresa como para o mercado, sendo, portanto caracterizado como inovação radical que é o tipo mais inovador. Os produtos com desempenho semelhantes aos existentes, no entanto apresentam reduções em termos de custo, sendo exemplos de produtos menos inovadores. Entre esse dois extremos encontram-se o reposicionamento (que se caracterizam como produtos já existentes, mas direcionados à novos mercados), a adição à linha de produtos existentes (que são produtos novos para a empresa e para o mercado), e melhoria de produtos existentes (são produtos considerados novos para a empresa, mas não para o mercado) (DANNELS e KLEINSCHMIDT, 2001).

Diante do exposto, observa-se que para o desenvolvimento das atividades inovadoras as empresas necessitam de estrutura e principalmente do conhecimento tecnológico necessário para o desenvolvimento do produto. Tendo em vista os elevados custos para manutenção de uma equipe que conheça o estado da arte sobre as pesquisas e tecnologia em sua área de atuação algumas empresas optam em desenvolver o produto em cooperação com outras empresas e/ou instituições de pesquisa, potencializando desta forma a troca de conhecimentos sobre as tendências tecnológicas e 
também dispor da infra-estrutura necessária para testar as inovações propostas (MANUAL OSLO, 1997).

Caracteriza-se como uma empresa ativamente inovadora em produto/processo aquela que implementou um produto ou processo novo ou significativamente melhorado durante o período de análise (MANUAL OSLO, 1997).

\subsection{Avaliação de Desempenho e seleção de Projetos Inovadores}

A Avaliação de Desempenho é um importante instrumento utilizado pelos gestores para avaliação e mensuração do desempenho organizacional, gerando informações úteis para auxiliar no processo de tomada de decisão. Inserido no contexto organizacional, encontra-se também o processo de seleção de projetos, que são realizados com uma finalidade específica que é adicionar valor tangível à organização (MARCHEWKA, 2003). Diante disso, surge a necessidade de avaliação e mensuração desses projetos com o objetivo de gerar informações para a identificação daquele que melhor atenda aos anseios da organização.

Em linhas gerais, ao investigar a literatura sobre o tema, verifica-se que poucos artigos apresentam uma definição de Avaliação de Desempenho e parece não haver um consenso entre os autores quanto à sua definição (ASTEBRO, 2004; ASOSHEH, NALCHIGAR e JAMPORAZMEY, 2010; HART, HULTINK, COMMANDEUR, 2003; LIGINLAL, RAM e DUCKSTEIN, 2006). Dessa forma, cumpre apresentar a afiliação teórica desta pesquisa no que diz respeito ao conceito de Avaliação de Desempenho que é o processo de gestão utilizado para construir, fixar e disseminar conhecimentos por meio de processo que identifica, organiza, mensura e integra os aspectos do contexto julgados relevantes, medindo em que grau é alcançado e gerando procedimento para melhorar o desempenho (ENSSLIN e ENSSLIN, 2010).

O processo de seleção de projetos inovadores é um dos fatores mais importantes no ambiente competitivo de hoje (OZER, 2003). A capacidade de uma empresa em desenvolver produtos inovadores é importante por diversas razões. A principal é que os produtos inovadores apresentam grandes oportunidades para as empresas em termos de crescimento e expansão em novas áreas, as inovações significativas permitem às empresas estabelecer posições competitivas dominantes, e proporcionar às novas empresas a oportunidade de ganhar uma posição no mercado (DANNEELS; KLEINSCHMIDT, 2001). No entanto, eles também estão associados a elevados riscos e desafios de gestão. Tais riscos e desafios se justificam: (i) em função da importância desses projetos para o desenvolvimento econômico e financeiro das empresas; (ii) os riscos e incertezas que envolvem o desenvolvimento desses produtos, no que diz respeito à tecnologia, à concorrência, aos clientes, à economia e a outros fatores ambientais, tendo em vista que os resultados somente serão conhecidos quando o produto se materializar (LIAO, 2001; OZER, 2003); (iii) altos custos 
com Pesquisa e Desenvolvimento (CARBONELL, ESCUDERO e ALEMAN, 2004); e (iv) elevadas taxas de insucesso (CARBONELL, ESCUDERO e ALEMAN, 2004).

Em função dos riscos e da diversidade de fatores a serem considerados no processo de seleção de projetos inovadores, a Avaliação de Desempenho representa um importante instrumento para identificação do projeto que deverá receber apoio financeiro para o seu desenvolvimento (CHO e LEE, 2005). Vários são os instrumentos utilizados no processo de seleção de projetos. Em uma revisão da literatura efetuada por Henriksen e Traynoor e Tritle et al. (2000 apud JACOB e KWAK, 2003), observaram-se os seguintes instrumentos: (i) revisão por pares não estruturados; (ii) programação matemática; (iii) modelos econômicos, como VPL e TIR; e, (iv) análise de decisão: teoria da utilidade, árvores de decisão, análise de risco e processo de hierarquia analítica.

Dentre os artigos analisados, também se identificaram várias instrumentos utilizados no processo de seleção de projetos, conforme apresentado no Quadro 1. Observa-se que nos artigos analisados por esta pesquisa, corroborando com os achados de Henriksen e Traynoor e Tritle et al. (2000 apud JACOB e KWAK, 2003), também houve a incidência predominante de modelos que se utilizam de programação matemática. Após a identificação das ferramentas (evidenciadas no Quadro 1), fez-se uma análise destas com o objetivo de identificar as similaridades e divergências à luz do conceito de Avaliação de Desempenho apresentado como afiliação teórica deste estudo. Para tanto, a partir do conceito de avaliação de desempenho proposto por Ensslin e Ensslin (2010), identificaram-se quatro aspectos que consideram mais importantes e que a ferramenta utilizada no processo de seleção dos projetos deve realizar. O primeiro aspecto diz respeito à identificação dos critérios a serem avaliados por meio de um processo estruturado; o segundo aspecto é em relação à mensuração, em que primeiro a mensuração é efetuada em escalas ordinais e posteriormente em escalas cardinais. O terceiro aspecto é relacionado à integração, ou seja, a ferramenta deve possibilitar a integração dos diversos descritores, possibilitando a obtenção de uma avaliação global do desempenho; e, por fim, no quarto aspecto, a ferramenta deve apresentar um processo de gerenciamento de forma a permitir que o gestor possa identificar as fragilidades e potencialidades dos descritores e, dessa forma, possibilitar o apoio ao processo de tomada de decisão (BORTOLUZZI, 2009). 
Quadro 1 - Análise das ferramentas encontradas nos artigos pesquisados à luz da afiliação teórica de AD

\begin{tabular}{|c|c|c|c|c|c|}
\hline Autor & Ferramenta & Identifica & Mensura & Integra & Gerencia \\
\hline $\begin{array}{l}\text { Loch } \\
(2001)\end{array} \quad$ et & $\begin{array}{l}\text { Programação } \\
\text { matemática }\end{array}$ & $\begin{array}{l}\text { Sim, os critérios } \\
\text { foram identificados } \\
\text { pelos gerentes de } \\
\text { projetos. }\end{array}$ & $\begin{array}{l}\text { Sim, a } \\
\text { mensuração é } \\
\text { efetuada de } \\
\text { forma } \\
\text { cardinal. }\end{array}$ & $\begin{array}{l}\text { Sim,, a } \\
\text { integração é } \\
\text { efetuada por } \\
\text { intermédio da } \\
\text { soma dos } \\
\text { critérios. }\end{array}$ & $\begin{array}{l}\text { Não, a } \\
\text { ferramenta não } \\
\text { apresenta um } \\
\text { processo de } \\
\text { gerenciamento. }\end{array}$ \\
\hline Åstebro, (2004) & $\begin{array}{l}\text { Modelos } \\
\text { estatísticos } \\
\text { (regressão } \\
\text { logística) }\end{array}$ & $\begin{array}{l}\text { Sim, os critérios são } \\
\text { identificados por } \\
\text { especialistas. }\end{array}$ & $\begin{array}{l}\text { Sim, a } \\
\text { mensuração é } \\
\text { efetuada } \\
\text { somente de } \\
\text { forma ordinal. }\end{array}$ & $\begin{array}{l}\text { Não, a } \\
\text { ferramenta não } \\
\text { se propõe a } \\
\text { efetuar a } \\
\text { integração dos } \\
\text { critérios. }\end{array}$ & $\begin{array}{l}\text { Não, a } \\
\text { ferramenta não } \\
\text { apresenta um } \\
\text { processo de } \\
\text { gerenciamento. }\end{array}$ \\
\hline $\begin{array}{l}\text { Linginlal, Ram } \\
\text { e Duckstein } \\
(2006)\end{array}$ & Modelo IP & $\begin{array}{l}\text { Sim, os critérios são } \\
\text { identificados por } \\
\text { meio de entrevistas } \\
\text { com os gestores. }\end{array}$ & $\begin{array}{l}\text { Sim, os } \\
\text { critérios são } \\
\text { mensurados de } \\
\text { forma global } \\
\text { por um perito. }\end{array}$ & $\begin{array}{l}\text { Não, a } \\
\text { ferramenta não } \\
\text { apresenta um } \\
\text { processo para } \\
\text { integrar os } \\
\text { indicadores. }\end{array}$ & $\begin{array}{l}\text { Não, apresenta } \\
\text { alternativas para } \\
\text { melhorar os } \\
\text { indicadores } \\
\text { apresentados. }\end{array}$ \\
\hline $\begin{array}{l}\text { Asosheh, } \\
\text { Nalchigar, e } \\
\text { Jamporazmey } \\
\text { (2010) }\end{array}$ & $\begin{array}{l}\text { Este trabalho } \\
\text { combina o } \\
\text { Balanced } \\
\text { Scorecard } \\
(B S C) \text { e a } \\
D E A\end{array}$ & $\begin{array}{l}\text { Sim, nesta fase do } \\
\text { processo é utilizado o } \\
B S C \text {. Os critérios de } \\
\text { avaliação foram } \\
\text { definidos por um } \\
\text { grupo de decisão, que } \\
\text { inclui vários } \\
\text { especialistas no } \\
\text { campo da gestão de } \\
\text { TI, BSC e engenharia } \\
\text { de software. }\end{array}$ & $\begin{array}{l}\text { Sim, a } \\
\text { mensuração é } \\
\text { efetuada } \\
\text { somente de } \\
\text { forma ordinal. }\end{array}$ & $\begin{array}{l}\text { Não, a } \\
\text { ferramenta não } \\
\text { apresenta um } \\
\text { processo para } \\
\text { integrar os } \\
\text { indicadores. }\end{array}$ & $\begin{array}{l}\text { Não, a } \\
\text { ferramenta não } \\
\text { apresentou } \\
\text { processo de } \\
\text { gerenciamentos } \\
\text { dos critérios. }\end{array}$ \\
\hline $\begin{array}{l}\text { Linginlal, Ram } \\
\text { e Duckstein } \\
(2006)\end{array}$ & Fuzzi & $\begin{array}{l}\text { Sim, os critérios são } \\
\text { identificados por } \\
\text { meio de entrevistas } \\
\text { com os gestores. }\end{array}$ & $\begin{array}{l}\text { Sim, os } \\
\text { critérios são } \\
\text { mensurados de } \\
\text { forma global } \\
\text { por um perito. }\end{array}$ & $\begin{array}{l}\text { Não, a } \\
\text { ferramenta não } \\
\text { apresenta um } \\
\text { processo para } \\
\text { integrar os } \\
\text { indicadores. }\end{array}$ & $\begin{array}{l}\text { Não, apresenta } \\
\text { processo para o } \\
\text { gerenciamento } \\
\text { dos critérios. }\end{array}$ \\
\hline
\end{tabular}

Analisando o Quadro 1, observa-se que em geral as ferramentas encontradas buscam identificar os critérios por meio de entrevista com os gestores, gerentes de projetos e especialistas; em relação à mensuração, somente duas ferramentas efetuam a mensuração de forma global; e a integração dos critérios é efetuada somente por uma ferramenta, sendo que nenhuma delas possibilita ao gestor a identificação dos aspectos que necessitam ser melhorados.

\section{Metodologia da Pesquisa}

Nesta seção, são descritos: (i) o enquadramento metodológico da pesquisa; e (ii) os procedimentos para construção do modelo.

\subsection{Enquadramento Metodológico}

Quanto à natureza do objetivo, este estudo se caracteriza como exploratório, por proporcionar familiaridade com o problema em estudo a fim de torná-lo explicito para a 
coordenadora do PJZ estudada. A maior familiaridade com o tema foi possível por meio da interação entre a coordenadora do programa e os facilitadores com o intuito de gerar conhecimento na coordenadora do programa e explicitar suas preocupações em relação às variáveis que impactam direta e/ou indiretamente nas características inovadoras das empresas, sendo que esses conhecimentos e preocupações se refletiram no modelo (GIL, 2010). No que tange à natureza do artigo é uma pesquisa prática, realizada por meio de um estudo de caso, no qual foi desenvolvido um modelo personalizado para a coordenadora do PJZ no estado de Santa Catarina (YIN, 2005).

Em relação à coleta de dados, esta pesquisa utilizou-se de dados primários e secundários (RICHARDSON, 2008). Os dados primários foram obtidos por intermédio de entrevistas com a coordenadora do programa em todas as fases de estruturação e avaliação do modelo. Os dados secundários foram obtidos por meio dos requisitos necessários para participar do programa expedido pela FINEP.

No que se refere à abordagem do problema, a presente pesquisa caracteriza como qualitativa-quantitativa (RICHARDSON, 2008). Qualitativa, no processo de estruturação do modelo onde são identificados os critérios, constroem-se as escalas ordinais e na fase de recomendações. Quantitativa no processo de avaliação onde as escalas ordinais são transformadas em cardinais e na integração dos critérios. A lógica da pesquisa é mista, indutiva na fase de estruturação e dedutiva na fase de avaliação ((ENSSLIN e ENSSLIN, 2008).

O instrumento de intervenção escolhido para a construção do modelo foi a Metodologia Multicritério de Apoio à Decisão Construtivista (MCDA-C), por se tratar de uma situação complexa onde a coordenadora do programa não possui de forma clara os critérios e deseja que os mesmos sejam construídos especificamente para este contexto levando em consideração seus valores e preferências. Conflituosos por envolverem múltiplos atores com interesses e preocupações distintas do decisor (ENSSLIN et al, 2010).

\subsection{Procedimento para Construção do Modelo}

Para atender ao propósito desta pesquisa o instrumento de intervenção utilizado é a Metodologia Multicritério de Apoio à Decisão Construtivista (MCDA-C). Apesar de o PJZ ser ofertado em vários estados brasileiros, convém destacar que o foco desta pesquisa é o estado de Santa Catarina, por intermédio do parceiro do Programa no estado de Santa Catarina a Associação Catarinense das Empresas de Tecnologia (ACATE).

A metodologia Multicritério de Apoio à Decisão Construtivista se difere das demais ferramentas de Avaliação de Desempenho, por levar em consideração as percepções do decisor, suas convicções e valores individuais durante o desenvolvimento do modelo de avaliação, permitindo a construção de um modelo único e personalizado ao contexto decisório em que se 
insere (ROY, 1993). O processo de desenvolvimento do conhecimento no decisor é realizado na metodologia MCDA-C de forma sistêmica e sistemática em três fases principais: (i) Estruturação; (ii) Avaliação; e (iii) Recomendações, conforme ilustrado na Figura 1.

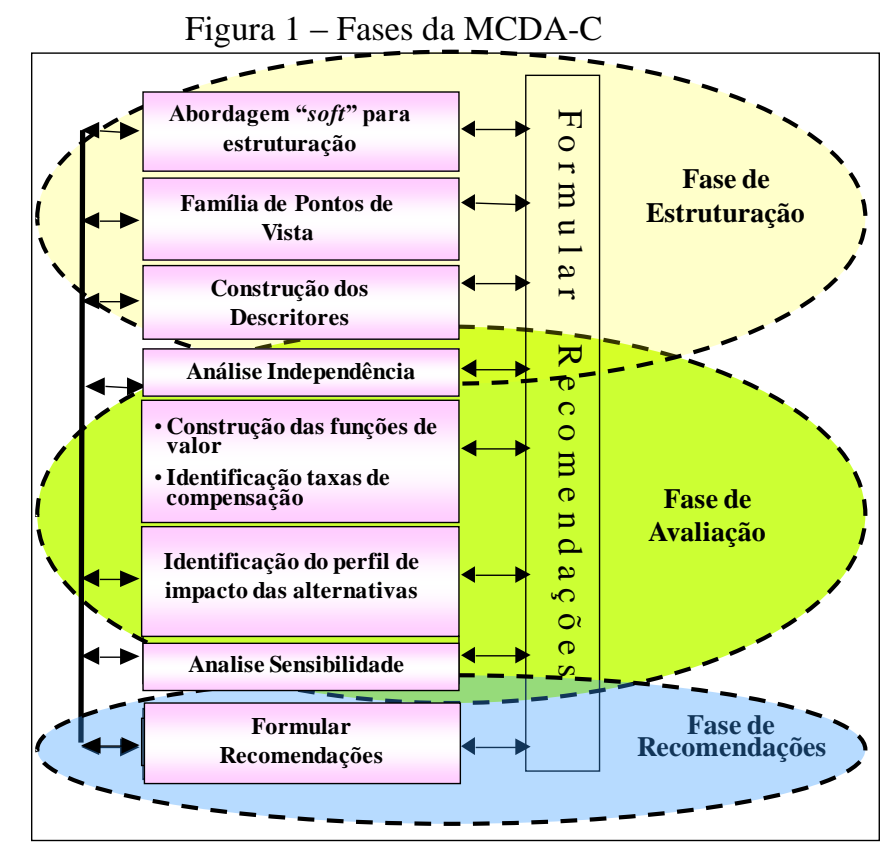

Fonte: Ensslin, Montibeller e Noronha, (2001)

$\mathrm{Na}$ fase de estruturação o contexto do problema é organizado a partir dos aspectos julgados mais relevantes pelo decisor. Para tanto, a contextualização consiste em apresentar o ambiente onde o problema esta inserido, por intermédio de uma descrição do contexto em que se indica o "dono" da insatisfação, a fonte da insatisfação, o desempenho atual e o desempenho pretendido. Além disso, é importante mencionar a relevância da situação e a sua factibilidade (se ela é passível de resolução) (CHECKLAND e SCHOLES, 1999).

Após a descrição do ambiente é apresentado os atores, ou seja, os indivíduos ou grupo de indivíduos que participarão direta ou indiretamente no processo de construção do modelo. Os atores envolvidos no processo podem ser: (i) intervenientes (stakeholders) que interferem diretamente no processo; (ii) agidos, que são os afetados pelas decisões, mas não tem poder para modificá-las; (iii) decisor, que é a pessoa, ou grupo, em nome de quem o Apoio à Decisão é feito; (iv) facilitador, que ajuda o decisor a identificar, organizar, mensurar e estabelecer os níveis de referência para as dimensões julgadas necessárias e suficientes para entender o contexto e assim compreender as conseqüências das diferentes decisões (LACERDA, 2009).

Identificado os atores o decisor juntamente com o facilitador define um rótulo que descreva o problema. O rótulo tem por função delimitar o contexto decisório, indicando o foco principal do problema a ser resolvido (ENSSLIN, MONTIBELLER e NORONHA, 2001).

A partir da contextualização do ambiente inicia-se o processo de construção propriamente dita do modelo. A primeira etapa para a construção do modelo é a definição dos Elementos 
Primários de Avaliação (EPAs). Os elementos primários de avaliação são as preocupações apresentadas pelo decisor quando questionários sobre o problema (ENSSLIN, MONTIBELLER e NORONHA, 2001). No intuito de incentivar o decisor a falar sobre as suas preocupações sobre o contexto a técnica utilizada foi o "brainstorming", e a partir destas informações o facilitador extraiu os EPAs.

Após a obtenção dos EPAs, é necessário expandir o entendimento sobre os mesmos, transformando os EPAs em conceitos orientados para a ação. O conceito deve estabelecer a direção de preferência do decisor ao mesmo tempo em que as fronteiras aceitáveis. Neste sentido, o conceito tem por objetivo estabelecer a direção de preferência desejada (pólo presente) associado ao EPA com seu respectivo pólo oposto psicológico que representa o desempenho que o decisor deseja minimizar ou evitar (ENSSLIN; MONTIBELLER; NORONHA, 2001).

A partir da formulação dos conceitos, realiza-se o agrupamento dos mesmos em áreas de afinidades ou cluster, desta forma é construída a hierarquia de conceitos meios-fins. A elaboração dos mapas meio-fins fará o decisor explicitar seus valores relacionados com o problema em questão (através de conceitos superiores na hierarquia), bem como fornecerá uma série de meios visando atingir os fins almejados (ENSSLIN; MONTIBELLER; NORONHA; 2001). Por meio da análise dos clusters do mapa meio-fins, são identificados os pontos de vista considerados como fundamentais pelo decisor e que serão levados em conta no modelo multicritério ((ENSSLIN; MONTIBELLER; NORONHA; 2001). Com base nos pontos de vista fundamentais é construída a Árvore de Pontos de Vista, a próxima etapa da fase de estruturação do modelo consiste na construção de escalas ordinais denominadas Descritores, que irão permitir a mensuração e a avaliação do desempenho local das ações potenciais (BORTOLUZZI, 2009, ENSSLIN et al, 2001).

A fase de avaliação tem por objetivo transformar as escalas ordinais dos descritores em cardinais, esta transformação é denominada de Funções de valor, este processo foi realizado com o auxilio do software MACBETH.

Segundo Lacerda (2009, p. 126) “a Função de Valor explicita a intensidade de preferência do decisor, sendo um instrumento que permite expressar as preferências dos decisores de forma cardinal, ou seja, são formas de expressar matematicamente, por meio de gráficos ou escalas numéricas, os julgamentos de valor dos decisores sobre um determinado critério." Para a transformação das escalas ordinais em cardinais, é necessário definir os níveis de referência para cada descritor, nível bom e neutro (também conhecido como ancoragem). Terminada a ancoragem, é importante identificar a diferença de atratividade entre os níveis determinados anteriormente; para tanto, cria-se uma função de valor para cada um deles, utilizando-se o método do julgamento semântico, por meio de comparações par-a-par e utilizando-se o software Macbeth (BANA e COSTA, STEWART e VANSNICK, 1995). 
A etapa seguinte da fase de Avaliação consiste na identificação das taxas de substituição que informam a diferença de atratividade entre os níveis do descritor. A partir da taxa de substituição de cada critério, podem-se transformar as avaliações locais em avaliação global. Para tanto, primeiramente ordenam-se os critérios e, na sequência, constrói-se a matriz semântica do julgamento de valor. Com isso procede-se a uma agregação das avaliações locais por meio da seguinte equação:

$$
V(a)=\sum_{j=1}^{n} k_{j} * v_{j}\left[g_{j}(a)\right]
$$

Onde,

$\mathrm{V}(\boldsymbol{a})=$ Valor global da alternativa $\boldsymbol{a}$

$\mathrm{g}_{\mathrm{j}}()=$. Descritor do PV j

$\mathrm{g}_{\mathrm{j}}(\boldsymbol{a})=$ Impacto da alternativa $\boldsymbol{a}$ no descritor gj

$\mathrm{V}_{\mathrm{j}}\left(\mathrm{g}_{\mathrm{j}}(\boldsymbol{a})\right)=$ Valor parcial da alternativa $\boldsymbol{a}$ no PV j

$\mathrm{k}_{\mathrm{j}}=$ Taxa de compensação do PVF $\mathrm{j}$

$\mathrm{n}=\mathrm{n}^{\mathrm{o}}$ de critérios do modelo

Na sequência para fornecer uma visão da estabilidade da performance das alternativas, os modelos permitem a realização de uma Analise de Sensibilidade no impacto das alternativas nas escalas, nas diferenças de atratividade das escalas cardinais e nas taxas de compensação (ENSSLIN et al, 2001). A análise de sensibilidade se propõe a verificar a robustez ou não das pontuações alternativas quando da variação das taxas de compensação e do impacto das alternativas nos níveis dos descritores. Esta análise pode ser efetuada manualmente, através do Excel ou com o auxilio do software Hiview, para esta pesquisa utilizou-se o software Hiview.

A fase de recomendações consiste na busca de ações que permitam melhorar a performance global em relação à situação atual, isto é possível por intermédio do conhecimento construído sobre o contexto. Esta fase é composta por duas etapas: (i) busca de oportunidade nos descritores; e (ii) busca de oportunidades nos recursos existentes.

A metodologia MCDA-C constrói os descritores de forma que a partir de cada nível é possível saber o que necessita para melhorar sua performance. Assim a partir de um dado perfil de impacto é possível visualizar onde se podem buscar oportunidades para melhorar a atratividade do contexto.

Outra oportunidade para buscar ações de recomendações que a metodologia MCDA-C proporciona é a busca de oportunidades nos recursos existentes. Essa etapa incentiva a reflexão sobre os recursos que o decisor possui e que poderiam ser utilizados para melhorar a atratividade das alternativas, existentes e potenciais (ENSSLIN e ENSSLIN, 2010). 


\section{Resultado: Construção do Modelo}

Nesta seção, apresentam-se os resultados do estudo de caso, realizado junto ao parceiro do Programa Juro Zero no estado de Santa Catarina. O estudo de caso foi construído levando-se em consideração as três fases da Metodologia Multicritério: (i) fase de estruturação; (ii) fase de avaliação; e (iii) fase de recomendações.

\subsection{Fase de Estruturação}

Nesta fase, o contexto do problema é estruturado e organizado a partir dos aspectos julgados relevantes pelo decisor. E busca gerar conhecimento sobre os seguintes aspectos: (i) contexto do problema, o subsistema de atores envolvidos no contexto e o rótulo do problema; (ii) Elementos primários de avaliação (EPAs) os conceitos orientados à ação e seu agrupamento por áreas de preocupação; (iii) mapas de relações meios-fins; e a (iv) estrutura hierárquica de valor e os descritores.

\subsubsection{Contextualização, Subsistema de Atores e Rótulo}

O estudo de caso foi desenvolvido junto ao parceiro do programa Juro Zero no Estado de Santa Catarina, a Associação Catarinense das Empresas de Tecnologia (ACATE).

As atividades inovadoras desenvolvidas pelas empresas vêm se caracterizando como fator fundamental para o desenvolvimento de diferenciais competitivos. No entanto um dos maiores obstáculos ao desenvolvimento de atividades inovadoras é a obtenção de recursos, sendo as instituições governamentais responsáveis por boa parte dos recursos investidos pelas empresas (CORDER e SALLES-FILHO, 2006). Com o intuito de apoiar a inovação tecnológica, a Financiadora de Estudos e Projetos (FINEP), empresa pública vinculada ao Ministério da Ciência e Tecnologia (MCT), lançou a Chamada Pública MCT/FINEP - Programa Juro Zero, em janeiro de 2004, com o objetivo de selecionar cinco instituições ou consórcios de instituições para serem seus parceiros estratégicos na implementação do programa em determinadas regiões/localidades do País.

Nesse processo, a FINEP selecionou cinco parceiros estratégicos para atuarem nos estados de Pernambuco, Minas Gerais, Paraná, Bahia e Santa Catarina. Em Santa Catarina (foco desta pesquisa), o convênio de cooperação institucional foi firmado entre a Associação Catarinense de Empresas de Tecnologia (ACATE) e a FINEP, em agosto de 2006.

Para obtenção do financiamento as MPEIs devem submeter seus projetos para avaliação. Por se tratar de uma situação complexa onde o decisor não possui de forma clara os critérios e deseja que os mesmos sejam construídos especificamente para este contexto levando em consideração seus valores e preferências o instrumento utilizado é a metodologia MCDA-C. O modelo construído permitirá a identificação, mensuração e integração dos aspectos julgados relevantes segundo a 
percepção do decisor, evidenciando o perfil de desempenho dos projetos nos aspectos críticos para o sucesso do programa.

Diante disso, fez-se a identificação dos atores envolvidos no contexto decisório, para identificação dos atores com poder de interferência no processo e aqueles com interesse nas decisões a serem tomadas. No Quadro 2 apresentamos o subsistema de atores envolvidos no contexto.

\begin{tabular}{|c|c|}
\hline & \\
\hline Decisor & Coordenadora do PJZ no Estado de SC \\
\hline \multirow{2}{*}{ Intervenientes } & Comitê Gestor \\
\hline & FINEP \\
\hline Facilitadores & Autores \\
\hline \multirow{2}{*}{ Agidos } & Empresas que submetem as propostas \\
\hline & Sociedade \\
\hline
\end{tabular}

Fonte: Pesquisa de campo (2011)

Posteriormente, por meio de um processo interativo entre os facilitadores e o decisor, elaborou-se um rótulo que represente da melhor forma possível as principais preocupações do decisor em relação ao problema. Para este estudo, foi proposto o seguinte rótulo: Avaliação das características inovadoras das propostas submetidas ao PJZ.

\subsubsection{Elementos primários de avaliação, conceitos e áreas de preocupação}

Uma vez definido o rótulo do problema, passa-se para o levantamento dos dados relativos ao sistema de valores por meio de entrevistas (técnica de brainstorming) com o decisor. Nas entrevistas foi solicitado ao decisor discorrer sobre o problema. Por intermédio da analise de suas declarações identificou-se os Elementos Primários de Avaliação (EPAs), que são as características ou propriedades do contexto que o decisor julga que impactam em seus valores (ENSSLIN et al, 2010). Por meio deste processo buscou-se identificar o maior número de EPAs possível, sendo que novos EPAs podem surgir com a combinação dos preexistentes. Neste processo identificou-se inicialmente 15 EPAs, conforme apresentado no Quadro 3.

Quadro 3 - EPAs Identificados

\begin{tabular}{|l|l|}
\hline \multicolumn{1}{|c|}{ EPA } & \multicolumn{1}{c|}{ Descrição } \\
\hline 1 & Parcerias \\
\hline 2 & Trajetória inovadora \\
\hline 3 & Origem tecnológica produtos oferecidos atualmente \\
\hline 4 & Caracterização da Inovação \\
\hline 5 & Existência de produto similar no mercado \\
\hline 6 & Substituição de produto importado \\
\hline 7 & Diferencial do produto \\
\hline 8 & Avaliação do projeto \\
\hline 9 & Tipos de inovação \\
\hline 10 & Experiência inovadora \\
\hline 11 & Atendimento ao quesito inovação \\
\hline 12 & Produtos desenvolvidos em parceria \\
\hline 13 & Histórico inovador \\
\hline
\end{tabular}




\begin{tabular}{|l|l|}
\hline 14 & Inovação para o mercado \\
\hline 15 & Novidade para o mercado \\
\hline
\end{tabular}

Fonte: Pesquisa de campo (2011)

Após a identificação dos EPAs, a metodologia MCDA-C, recomenda expandir o entendimento do decisor por meio da identificação da direção de preferência representada por cada EPA, bem como seu pólo oposto psicológico, objetivando construir o entendimento sobre o grau mínimo de aceitabilidade do objetivo subjacente. Neste processo os EPAs foram transformados em conceitos orientados para a ação (EDEN, 1988). Para a obtenção dos conceitos é solicitado ao decisor que fale detalhadamente a respeito do EPA, possibilitando a identificação do desempenho melhor possível; o desempenho bom; o desempenho ruim; o desempenho pior possível (mas aceitável) e a performance atual. Essa intensidade se reflete no verbo a ser utilizado na construção de cada conceito. O Quadro 4 exibe os conceitos orientados à ação para os 5 primeiros EPAs, onde a reticências (...) deve ser lida como "é preferível a" ou "ao invés de" e corresponde ao oposto psicológico.

Quadro 4 - Exemplo de conceito orientados à ação para os 5 primeiros EPAs

\begin{tabular}{|c|c|}
\hline Conceito & Descrição \\
\hline C 1 & $\begin{array}{l}1 \text {-Possuir contrato de parceria com instituições de pesquisa, universidades, dentre outros } \\
\text { para incentivar trabalhos de inovação... Deixar de conhecer o estado da arte de pesquisas } \\
\text { em sua área de atuação. } \\
2 \text { - Ter contrato de parceria com instituições de pesquisa, universidades, dentre outros para } \\
\text { o desenvolvimento do produto... Deixar de poder utilizar infra-estrutura para gerar e ou } \\
\text { testar conhecimentos inovadores. }\end{array}$ \\
\hline C 2 & $\begin{array}{l}\text { 3-Analisar se às empresas possuem trajetória na implementação de atividades inovadoras... } \\
\text { Investir em empresas com pouca experiência no desenvolvimento de produtos inovadores. }\end{array}$ \\
\hline C 3 & $\begin{array}{l}\text { 4-Averiguar se os produtos e/ou serviços comercializados pela empresa atualmente são de } \\
\text { origem tecnológica própria... Investir em empresa sem característica inovadora. }\end{array}$ \\
\hline C 4 & $\begin{array}{l}\text { 5- Analisar se o projeto atende a concepção de um novo produto ou processo de } \\
\text { fabricação... Investir em projetos que não atendam às características do programa. } \\
\text { 6- Verificar se o produto objeto do projeto possui características que representem inovação } \\
\text { de produto e processo... Investir em projetos que não atendam às características do } \\
\text { programa. } \\
\text { 7- Analisar em caso de melhorias incrementais se as melhorias implicam em efetivos } \\
\text { ganho de qualidade ou produtividade... Investir em projetos que não atendam às } \\
\text { características do programa. } \\
\text { 8- Analisar se o produto/processo ou serviço representará maior competitividade no } \\
\text { mercado.... Investir em projetos que não atendam às características do programa. }\end{array}$ \\
\hline C 5 & $\begin{array}{l}\text { 9- Identificar a existência de produto igual ou similar à proposta submetida.... Investir em } \\
\text { projetos que não atendam às características do programa. }\end{array}$ \\
\hline
\end{tabular}

Fonte: Pesquisa de campo (2011)

Os conceitos que representam preocupações estratégicas equivalentes, segundo a percepção do decisor, são agrupados em Áreas de Preocupação que direta ou indiretamente causam impacto na Avaliação das características inovadoras das propostas submetidas ao PJZ. Na Figura 2 evidencia ás áreas de preocupação para o Estudo de caso e a numeração dos respectivos conceitos que as compõem. 
Figura 2 - Agrupamento dos conceitos por Áreas de Preocupação

Ava liação das características inova doras das propostas submetidas ao PJZ

\begin{tabular}{|c|}
\hline Parcerias \\
\hline Conceitos: \\
\hline $1,2,17$ \\
\hline
\end{tabular}

\begin{tabular}{|c|}
\hline Trajetória \\
\hline Inovadora \\
\hline Conceitos: \\
\hline $3,4,18$ \\
\hline
\end{tabular}

\begin{tabular}{|c|}
\hline $\begin{array}{c}\text { Tipos de } \\
\text { Inovação }\end{array}$ \\
\hline $\begin{array}{c}\text { Conceitos: } \\
6,13\end{array}$ \\
\hline
\end{tabular}

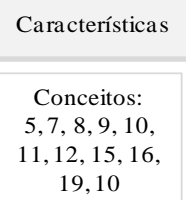

Fonte: Pesquisa de campo (2011)

\subsubsection{Mapas de relações meios fins}

A partir dos conceitos geradores das áreas, a metodologia MCDA-C expande o entendimento através da identificação das relações de hierarquia e das relações de influência entre os conceitos. Pela elaboração dos mapas meio-fins, a coordenadora irá explicitar seus valores relacionados ao problema em questão (por meio de conceitos superiores na hierarquia), bem como fornecerá uma série de meios visando atingir os fins almejados (ENSSLIN; MONTIBELLER e NORONHA; 2001).

Com o objetivo de facilitar o entendimento e sua análise, o mapa de relação meio-fins é dividido em mapas menores formando os clusters. Os clusters são formados por meio do agrupamento dos ramos cuja argumentação reflita uma mesma preocupação do decisor e não existam relações de influência entre os clusters. A Figura 3 ilustra o Mapa de relação Meio-Fins para o Cluster Produto a ser desenvolvido.

Figura 3 - Mapa Meio-Fins para o Cluster Produto a ser desenvolvido

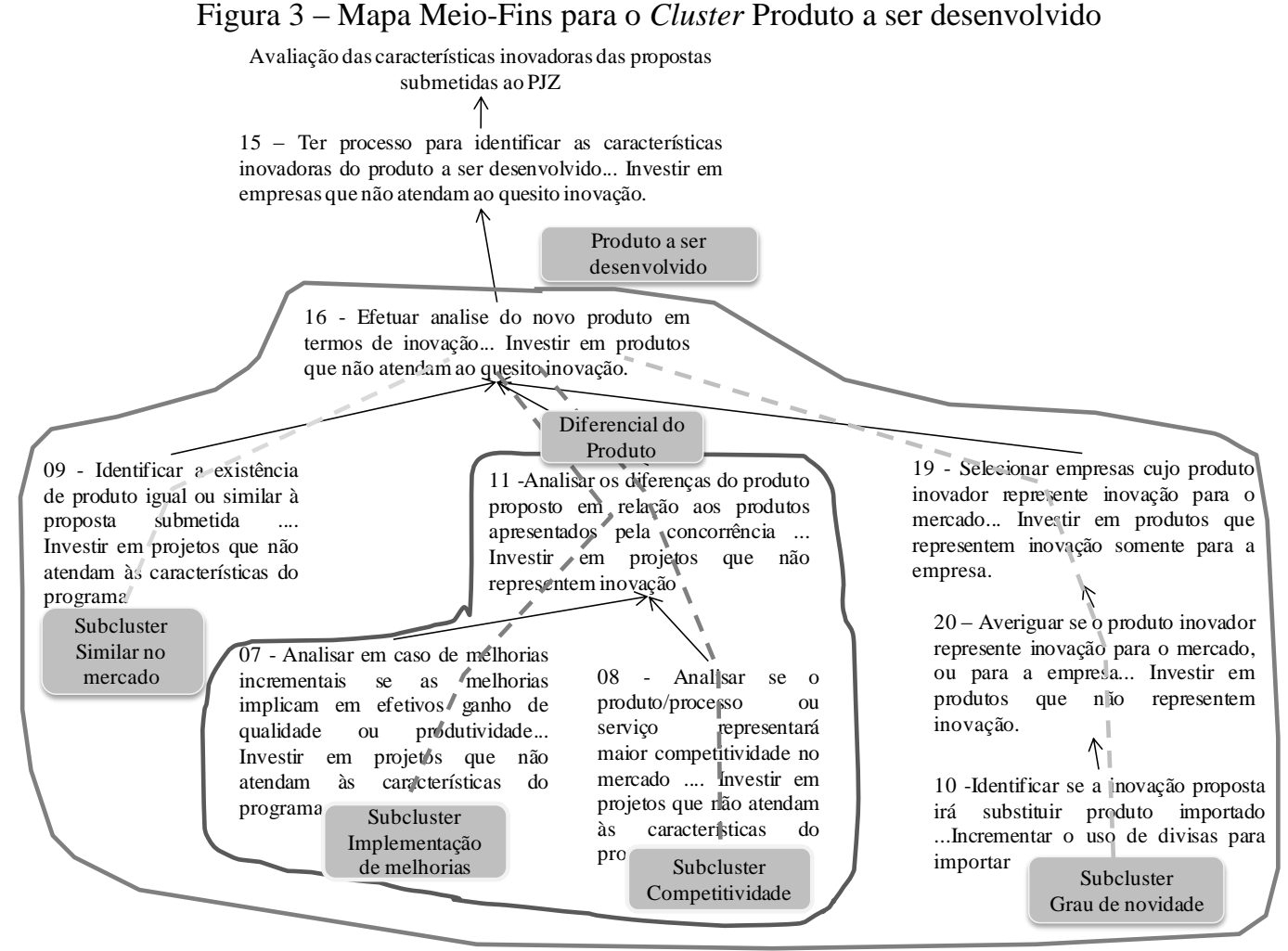

Fonte: Pesquisa de campo (2011) 


\subsubsection{Estrutura Hierárquica de Valor e Descritores}

Após a construção de todos os mapas, dando continuidade ao processo de construção do entendimento, a metodologia MCDA-C, propõe que a relação de influência seja convertida em uma estrutura hierárquica de valor, permitindo incorporar o entendimento dos julgamentos preferenciais do decisor no modelo em construção (KEENEY, 1992; ENSSLIN; GIFFHORN, ENSSLIN, PETRI e VIANA, 2010).

Os clusters iniciais necessitam ser testados para identificar se os aspectos do contexto estão representados de forma: essencial, controlável, completo, mensurável, operacional, isolável, nãoredundante, conciso e compreensível (ENSSLIN; MONTIBELLER e NORONHA; 2001, ENSSLIN, GIFFHORN, ENSSLIN, PETRI e VIANA, 2010). Ao serem analisados muitos clusters iniciais necessitam ser desmembrados até atenderem as propriedades acima mencionadas.

Através do mapa de relação meio-fins e sua organização em áreas de preocupação, é possível identificar a Estrutura Arborescente ou Pontos de Vista Fundamentais (PVFs). É importante ressaltar que esta Estrutura Arborescente utiliza a lógica da decomposição, em que os PVFs são desdobrados em Pontos de Vistas Elementares (PVEs) até um nível possível de ser mensurado (ibid.). Esse nível corresponde os aspectos/fatores que respondem pelo desempenho das propostas submetidas. A Figura 4 apresenta a Estrutura Arborescente para o modelo construído neste estudo.

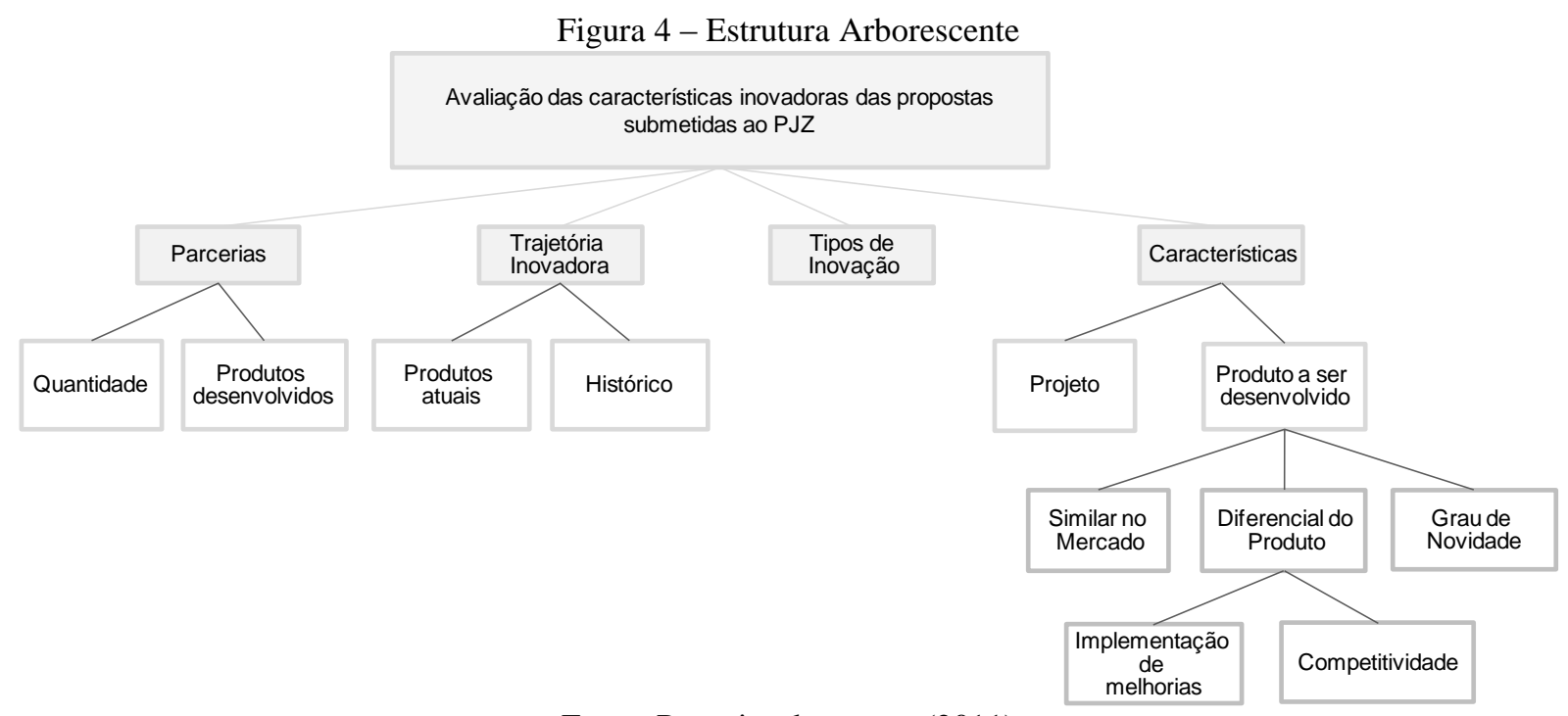

Fonte: Pesquisa de campo (2011)

Uma vez construída a Estrutura Arborescente, o passo seguinte é a construção de escalas ordinais para mensurar os pontos de vistas, estas escalas ordinais são denominadas de Descritores. As escalas ordinais são construídas em um processo interativo com o decisor, onde para cada descritor são definidos níveis de impacto, dentre eles são estabelecidos os níveis de referência Bom e Neutro, em que os níveis acima do nível Bom são considerados benchmarking; abaixo do nível 
Neutro são considerados comprometedores, e os níveis intermediários (entre o nível Bom e Neutro) são considerados níveis de mercado (ENSSLIN; MONTIBELLER; NORONHA, 2001; ENSSLIN; DUTRA; LYRIO, 2006).

A partir dessa transição, foi possível identificar 10 indicadores de avaliação. No entanto, ao concluir a construção da Estrutura Hierárquica de Valor com os Descritores, foi possível desenvolver todo o entendimento do contexto permitido por uma estrutura não numérica (escalas nominais e ordinais). Dando continuidade ao processo de entendimento, as escalas ordinais devem ser transformadas em cardinais, que é o propósito da fase seguinte da metodologia MCDA-C.

\subsection{Fase de Avaliação}

A Fase de Avaliação do modelo busca abordar os seguintes aspectos: (i) construção das Funções de Valor; (ii) determinar as Taxas de Substituição; e, (iii) realizar a Avaliação Global e Perfil de Impacto do status quo. A fase de avaliação tem por objetivo melhorar o entendimento do decisor por meio da construção de escalas cardinais e taxas de substituição que representem suas preferências locais e globais.

\subsubsection{Função de Valor}

A MCDA-C reconhece as diferenças entre as escalas ordinais e cardinais, por tanto nesta fase, os dados até então apresentados e organizados de forma qualitativa serão transformados em dados quantitativos, possibilitando a avaliação das características inovadoras das propostas submetidas ao PJZ em cada um dos critérios julgados relevantes pelo decisor. Para tanto, a primeira etapa a ser desenvolvida é a construção das funções de valor (escalas cardinais).

O processo de transformação das escalas ordinais em cardinais pode ser feito manualmente (através do método pontuação direta, bissecção, dentre outras) ou utilizando-se de softwares desenvolvidos para este propósito. Nesta pesquisa é utilizado o software MACBETH para transformação das escalas ordinais em cardinais. A partir dos julgamentos semânticos proferidos pela coordenadora do PJZ perante a ACATE, atribui-se notas a cada nível do descritor, considerando os níveis âncoras é calculada as funções de valor dos critérios do modelo. Cumpre ressaltar que aos níveis Bom e Neutro é atribuída respectivamente a pontuação 100 e 0 . A Figura 4 apresenta transformação do descritor (escala ordinal) do aspecto "Parcerias" para escala cardinal. 
Figura 4 - Transformação do Descritor do aspecto "Quantidade" em Função de Valor por meio do software M$M A C B E T H$
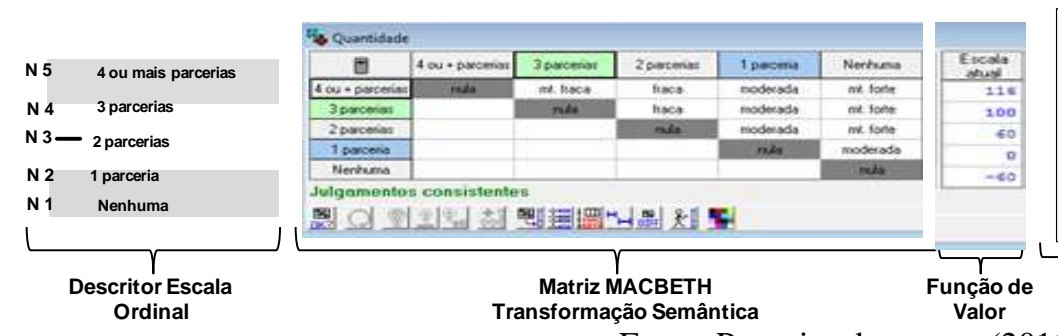

Fonte: Pesquisa de campo (2011)

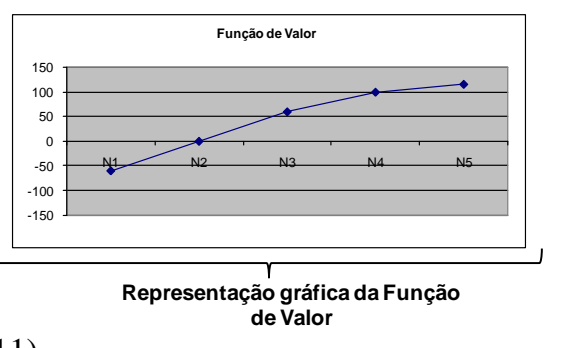

Por meio da matriz MACBETH, apresentada na Figura 4, pode-se observar a perda de atratividade percebida pelo decisor, quando da passagem de um nível para outro no descritor. Ao concluir a etapa de construção das funções de valor, a metodologia MCDA-C proporciona ao decisor um entendimento que lhe possibilita mensurar cardinalmente cada aspecto operacional considerado relevante.

\subsubsection{Taxas de Substituição}

A etapa seguinte no processo de construção do entendimento consiste em agregar as avaliações locais dos critérios em uma avaliação global, possibilitando ao coordenador do programa analisar as características inovadoras das diferentes propostas submetidas ao programa. Tal etapa consiste na identificação das taxas de substituição, que representam a importância de cada critério no modelo. O método utilizado foi o de comparação par a par do software MACBETH. Inicia-se com a criação de ações potenciais que representem a contribuição da passagem do nível Neutro para o nível Bom, em cada um dos critérios que se desejam determinar a taxas, e também a criação de ações de referencia com o desempenho neutro em todos os pontos de vista (A-0) que neste caso será utilizado como uma ancoragem, recebendo assim, uma importância de $0 \%$.

Após a criação das ações de referência, as alternativas devem ser ordenadas. Nesta pesquisa, a ordenação foi efetuada utilizando-se a Matriz de Roberts, em que o decisor forneceu informações sobre as alternativas potenciais construídas segundo o seu juízo preferencial. As alternativas ordenadas foram inseridas no software MACBETH, que, valendo-se da lógica apresentada na Figura 4 , fornece as taxas de substituição, sendo este processo realizado para todos os níveis hierárquicos da Árvore de Valores. As taxas devem ser obtidas partindo inicialmente dos níveis hierárquicos inferiores até os superiores (ENSSLIN, MONTIBELLER e NORONHA, 2001).

\subsubsection{Avaliação Global e Perfil de Impacto do status quo}

Uma vez obtidas as funções de valor e as taxas de substituição dos descritores pode-se construir a equação geral do modelo. Para tanto, é necessário efetuar a agregação das avaliações locais por meio da equação matemática de agregação aditiva. Após a agregação das avaliações 
locais, pode-se utilizar o modelo para apoiar no processo de avaliação das características inovadoras das propostas submetidas.

No presente estudo, a avaliação global foi elaborada de acordo com o perfil de desempenho de duas propostas submetida ao programa pelas Empresas "X" e "Y" (escolhidas para exemplificar o modelo). Com o suporte do modelo de avaliação global, a coordenadora do programa identificou a pontuação e o perfil de desempenho das duas propostas submetidas pelas empresas em relação às características inovadoras, conforme evidenciado na Figura 5.

Figura 5 - Perfil de Impacto do status quo da proposta das Empresas "X" e "Y"

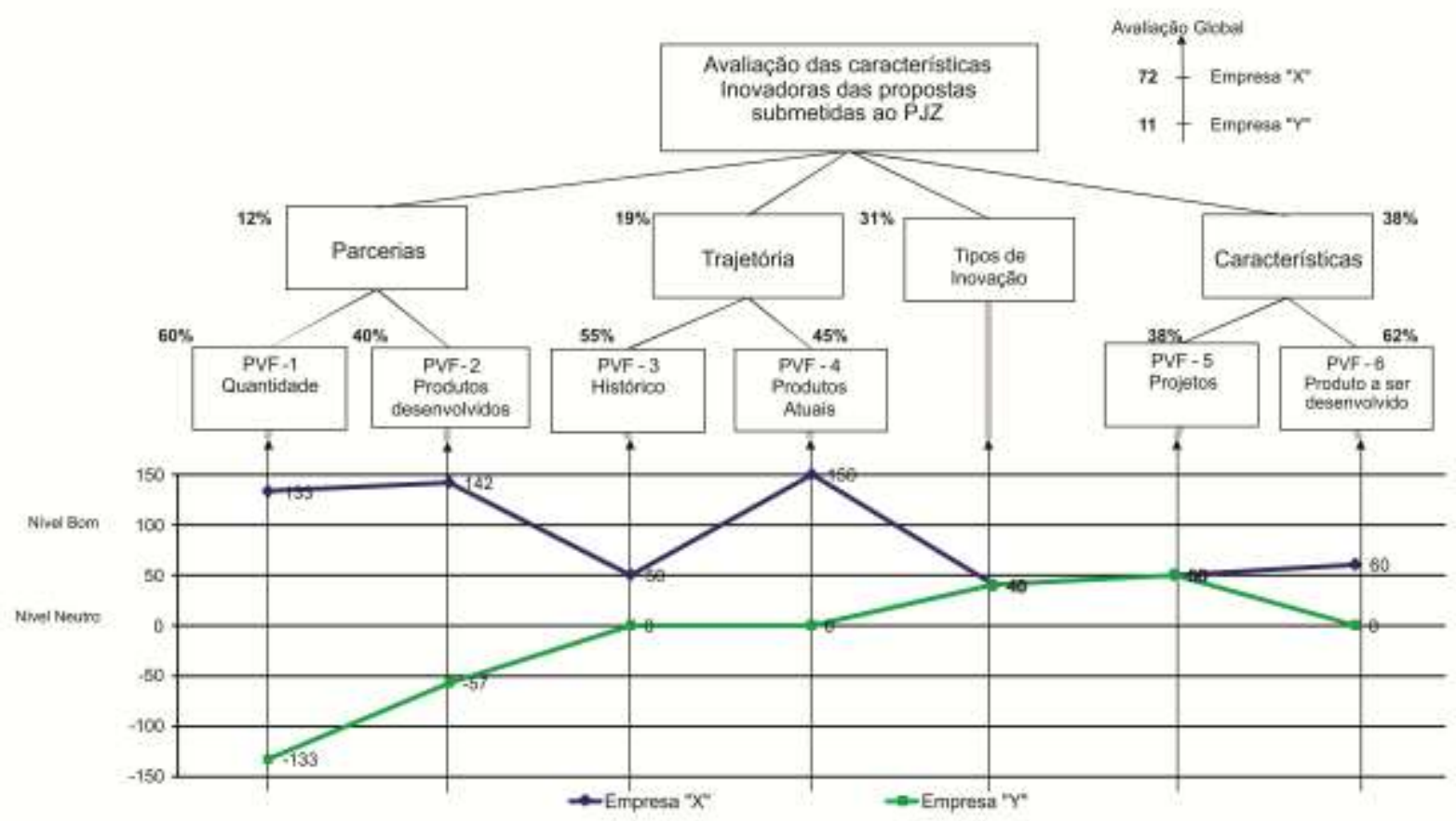

Fonte: Pesquisa de campo (2011)

De acordo com as informações da Figura 5, observa-se que o perfil de desempenho da proposta " $X$ " está alinhado com os critérios estratégicos, uma vez que a avaliação global da proposta submetida pela empresa foi de 72 pontos, o que se configura como um desempenho em nível competitivo em uma escala onde 0 pontos equivale ao nível Neutro e, 100 pontos equivale ao nível bom. Já a Empresa "Y" apresenta um perfil de desempenho de 11 pontos, mesmo apresentando um desempenho competitivo, a empresa apresenta vários critérios em nível comprometedor, quais sejam: Quantidade, Produtos desenvolvidos, Histórico, Produtos atuais, e Produto a ser desenvolvido.

Em linhas gerais, as informações geradas a partir do modelo possibilitaram à coordenadora identificar de forma específica os critérios em que as empresas necessitam atuar para que suas propostas sejam aceitas, gerando assim transparência no processo de seleção das empresas. Como forma de gerenciar os recursos e auxiliar as empresas, a coordenadora do programa pode ainda identificar ações e avaliar seu impacto para que as empresas alcancem seus objetivos que, nesse 
caso, é conseguir o financiamento para o desenvolvimento de um produto inovador que proporcione melhoria em seu desempenho econômico e financeiro. A etapa de identificação e avaliação de ações é denominada Recomendações, que será abordada a seguir.

\subsection{Recomendações}

Esta etapa tem por função servir de apoio às empresas no sentido de identificar ações para melhorar o desempenho das propostas avaliadas em relação às características inovadoras, assim como entender as conseqüências destas ações na melhoria do perfil de desempenho das propostas, caso as ações venham a ser implementadas.

O processo de geração de ações de recomendação é elaborado com base nos descritores cujo desempenho não atendeu às expectativas, ou seja, aqueles desempenhos que se encontram em níveis comprometedores. No caso da Empresa "Y" caso esta empresa implementasse ações estratégicas como: Estabelecer 2 parcerias para o desenvolvimento do produto, possuir 1 produto desenvolvido em parceria com instituições de pesquisa nos últimos dois anos, e aumentar o número de diferencias competitivos do produto, o perfil de desempenho do status quo da proposta de 11 pontos, passaria para 29 pontos, conforme evidenciado na Figura 6.

Figura 6 - Perfil de Impacto do status quo e após implantação ações estratégicas na proposta da Empresas "Y"

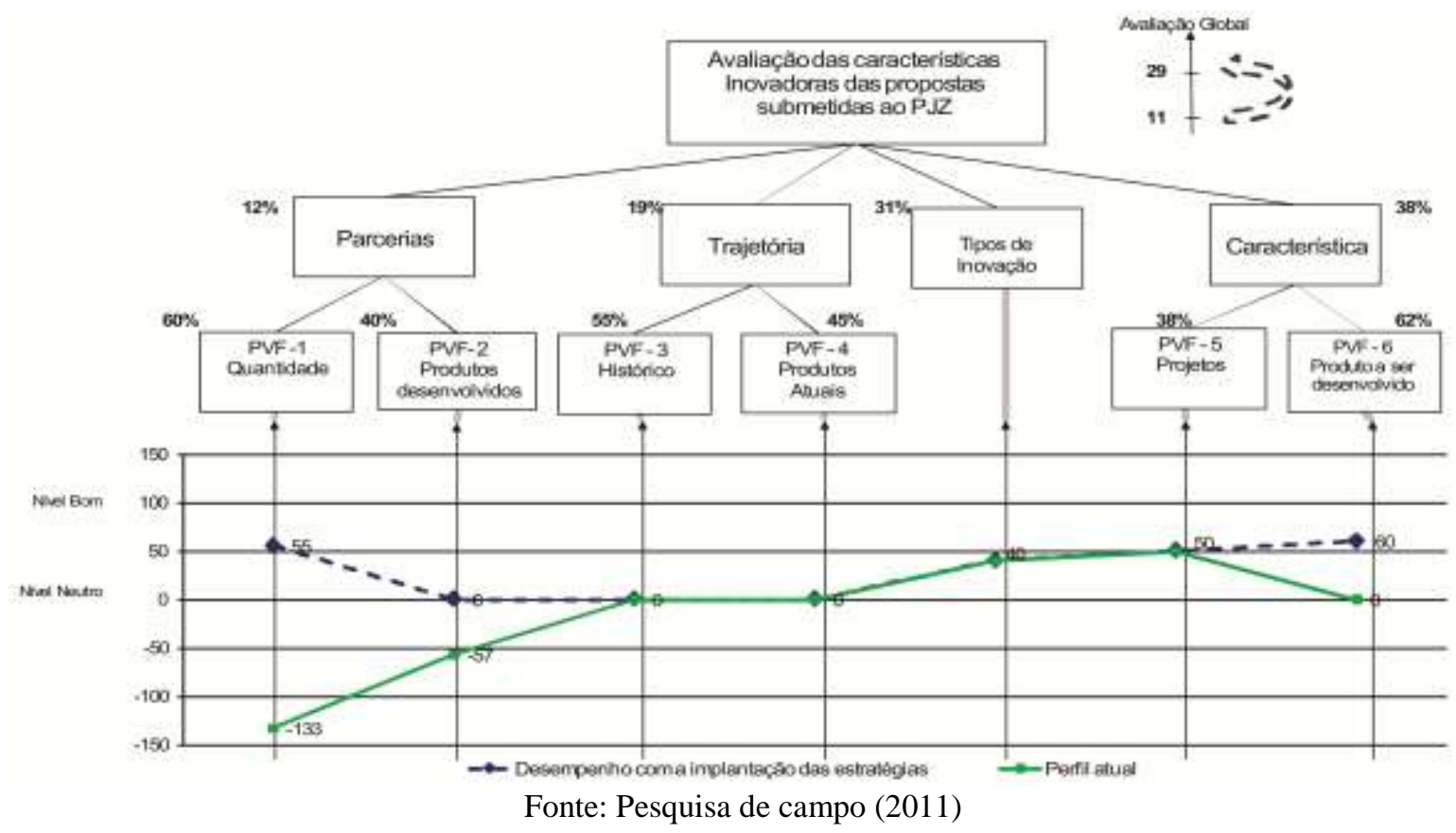

Percebe-se assim, as vantagens na construção de um processo para auxiliar na seleção das propostas submetidas ao programa. Esse processo apresenta vantagens para a coordenadora do programa, por possibilitar a construção do entendimento sobre os aspectos relevantes a serem considerados no processo de avaliação das propostas e também para as empresas que submetem 
suas propostas, possibilitando a identificação dos aspectos de suas propostas que necessitam ser melhorado.

\section{Considerações Finais}

O presente artigo objetivou construir o entendimento do decisor, materializado em um modelo para avaliação das características inovadoras das propostas, de forma a auxiliar na gestão do processo de qualificação das propostas submetidas pelas Micro e Pequenas Empresas Inovadoras de Santa Catarina ao PJZ. Na busca de resposta ao problema central da pesquisa, foram formulados os seguintes objetivos específicos: (i) construir entendimento da questão pela identificação dos aspectos que a Coordenadora do PJZ no estado de Santa Catarina considera necessários e suficientes para avaliação das características inovadora das empresas; (ii) construir escalas ordinais e cardinais para os aspectos identificados; (iii) integrar os aspectos via taxas de compensação, conforme a percepção da coordenadora; e (iv) ilustrar o perfil do desempenho de duas proposta submetidas ao PJZ.

A metodologia MCDA-C trabalha com processos personalizados aos atores e ao contexto decisório. Dessa forma, o processo de construção do modelo teve início com a contextualização e explicitação dos atores envolvidos, sendo eles o decisor, os agidos, os intervenientes e os facilitadores. Por intermédio de entrevistas com o decisor, foram identificados os elementos primários de avaliação, mediante o processo de construção de conhecimento no decisor os elementos primários de avaliação foram transformados em conceitos orientados à ação. Os conceitos foram agrupados em mapas de relação meio-fins, com o objetivo de identificar as relações de influência entre os conceitos. Como resultados desse processo foram identificados os 10 critérios a serem tidos em conta para avaliação das das características inovadoras das propostas que são: 1Quantidade; 2- Produtos desenvolvidos; 3- Histórico; 4- Produtos atuais; 5 - Tipos de Inovação; 6 Projeto; 7 - Similar no mercado; 8 - Implementação de melhorias; 9- Competitividade; 10 - Grau de novidade, atingindo assim o primeiro objetivo específico.

Para cada descritor o decisor construiu escalas ordinais, no entanto como essa escala não admite a realização de operações numéricas, realizou-se a transformação das escalas ordinais em cardinais. Esta transformação foi realizada na fase de avaliação, e possibilita a identificação da diferença de atratividade entre os níveis de cada descritor, atendendo ao segundo objetivo específico.

Após a construção das escalas cardinais para cada descritor, realizou-se a integração entre os critérios por meio da identificação das taxas de substituição, que em conjunto com as funções de valor possibilitam a avaliação global de desempenho das características inovadoras das propostas submetidas ao programa cumprindo o terceiro objetivo específico desta pesquisa. 
A partir do modelo construído, foi possível avaliar o perfil de desempenho das propostas submetidas pelas Empresas "X" e "Y", possibilitando a identificação dos critérios onde as empresas encontram-se com desempenho comprometedor bem como gerar ações de aperfeiçoamento que possa melhorar o resultado da avaliação local, ou seja, ações que melhorem pontualmente um descritor, assim como entender as conseqüências destas ações na melhoria na avaliação global das propostas, caso as ações venham a ser implementadas, atendendo ao quarto objetivo específico.

Dessa forma, conseguiu-se elaborar um modelo de avaliação das características inovadoras que considerou indicadores qualitativos e quantitativos e respeitou as particularidades do programa.

Em linhas gerais, as informações geradas a partir do modelo possibilitaram à coordenadora do programa identificar de forma específica os critérios em que as empresas necessitam atuar para que suas propostas sejam aceitas, gerando assim transparência no processo de seleção das empresas.

Quanto aos critérios identificados neste estudo, que respondem pelo desempenho das características inovadoras das propostas submetidas, estes estão em consonância com os aspectos apontados na literatura em relação à inovação tecnológica, bem como agregam ainda novas preocupações específicas ao contexto estudado (DANNELS e KLEINSCHMIDT, 2001; MANUAL OSLO, 1997).

Por meio de uma análise do modelo construído nesta pesquisa com as ferramentas identificadas na literatura (Quadro 1) para seleção de projetos, constata-se que a metodologia MCDA-C se destaca das demais por: (i) proporcionar aos atores envolvidos no contexto decisório sua participação em todas as etapas do processo, possibilitando-lhes a construção de conhecimento sobre o contexto decisorial, onde tal conhecimento resultará em um modelo que reflita seus valores e preferências; e (ii) por ser uma ferramenta que possibilita a identificação, mensuração, integração e um processo para gerenciamento de ações que possibilitem uma melhoria nos critérios em que a empresa apresenta um desempenho comprometedor.

Como principal limitação da pesquisa, ressalta-se os seguintes aspectos: (i) o caráter de personalização da mesma, tendo em vista que o modelo fora construído segundo os valores e preferências de um decisor específico; e (ii) as estratégias elaboradas na fase de recomendações foram simulações de cenários.

Sugere-se para futuras pesquisas: (i) que o contexto desta pesquisa seja analisado segundo a percepção do coordenador do programa em outro estado, possibilitando verificar a similaridade, ou não, de preocupações entre os parceiros com relação às características inovadoras a serem analisadas nas propostas submetidas ao PJZ; e (ii) a continuidade da construção do modelo para os outros aspectos a serem considerados no processo de avaliação das propostas submetidas ao PJZ. The research characterizes the qualitative and quantitative structuring phase in the evaluation phase. 


\begin{abstract}
This research aims to build a model for evaluation of the innovative features of the proposals in order to assist in managing the process of qualification of the bids submitted by the Santa Catarina's IMSEs (Innovative Micro and Small Enterprises) the Zero Interest Program, using Methodology of Multicriteria Decision Aiding Constructivist (MCDA-C). The research is characterized as a case study, for data collection using the technique of interview and documentary analysis with qualitative and quantitative structuring phase in the evaluation phase. The intervention instrument adopted is the Methodology of Multicriteria Decision Aiding Constructivist (MCDA-C). The results show from the knowledge generated was possible to construct a model that enabled the program coordinator: (i) identify the 20 criteria that make up the model for evaluation of the innovative features the proposal submitted to Zero Interest Program; (ii) build cardinal and ordinal scales for each indicator; (iii) evaluate the performance profile (status quo) of two proposal submitted to the program; (iv) identify the indicators and generate compromising performance improvement actions that can improve the performance profile of the proposals. It is concluded that the information generated from the model enable the coordinator of the program see the performance profile of the proposals submitted, providing transparency in the selection process of companies. It also allows companies to identify specifically the criteria that need to improve their proposals are accepted.
\end{abstract}

Key-words: project selection; performance evaluation; MCDA-C; technological innovation.

\title{
Referências
}

ASTEBRO, T. Key success factors for technological entrepreneurs' R\&D projects. IEEE Transactions on Engineering Management, v. 51, n. 3, p. 314-321, 2004.

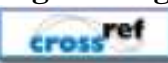

ASOSHEH, A.; NALCHIGAR, S.; JAMPORAZMEV, M. Information technology project evaluation: An integrated data envelopment analysis and balanced scorecard approach. Expert Systems with Applications, v. 37, n. 8, p.59315938, August 2010

cross ref

BITMAN, W. R.; SHARIF, N. A conceptual framework for ranking R\&D projects. IEEE Transactions on Engineering Management, v.55, n. 2, p. 267-278, May 2008.

\section{cross ref}

BORTOLUZZI, S. C. Avaliação de Desempenho Econômico-financeiro da Empresa Marel Indústria de Móveis S.A.: A Contribuição da Metodologia Multicritério de Apoio à Decisão Construtivista (MCDA-C). Dissertação de Mestrado (Mestrado em Contabilidade). Programa de Pós-Graduação em Contabilidade. Universidade Federal de Santa Catarina, Florianópolis, 2009.

; ENSSLIN, S. R; ENSSLIN, L. Avaliação de Desempenho dos Aspectos Tangíveis e Intangíveis da Área de Mercado: estudo de caso em uma média empresa industrial. Revista Brasileira de Gestão de Negócios, São Paulo, v. 12, n. 37, p. 425-446, out./dez. 2010.

BRASIL. Lei n. 11.196, de 21 de novembro de 2005. Institui o Regime Especial de Tributação para a Plataforma de Exportação de Serviços de Tecnologia da Informação - REPES, o Regime Especial de Aquisição de Bens de Capital para Empresas Exportadoras - RECAP e o Programa de Inclusão Digital e dispõe sobre incentivos fiscais para a inovação tecnológica; e dá outras providências. Disponível em: <www.planalto.gov.br/>. Acesso em: 15 dez. 2010.

CARBONELL, P.; ESCUDERO, A. I. R.; ALEMAN, J. L. M. Technology newness and impact of go/no-go criteria on new product success. Marketing Letters, v.15, n. 2-3, p. 81-97, July/October 2004.

cross ref

CHO, E. S.; LEE, M. An exploratory study on contingency factors affecting R\&D performance measurement. International Journal of Manpower, v. 26, n. 6, p. 502-512, 2005. 
CORDER, S.; SALLES-FILHO, S. Aspectos conceituais do financiamento à inovação. Revista Brasileira de Inovação, Rio de Janeiro, v. 5, n. 1, p. 33-76, jan./jun. 2006.

DANNEELS, E; KLEINSCHMIDT, J. Product innovativeness from the firm's perspective: Its dimensions and their relation with project selection and performance. Journal of Product Innovation Management, v. 18, n.6, p. 357-373, November 2001.

cross ref

EDEN, C. Cognitive mapping. European Journal of Operational Research, v. 36, p. 01-13, 1988.

ENSSLIN, L.; ENSSLIN, S. R. Notas de aula da disciplina CCN 3518 - Introdução à MCDA. Programa de PósGraduação em Contabilidade da Universidade Federal de Santa Catarina. Mimeo: Florianópolis, 2010.

ENSSLIN, L.; MONTIBELLER NETO, G.; NORONHA, S. M. Apoio à decisão: metodologia para estruturação de problemas e avaliação multicritério de alternativas. Florianópolis: Insular, 2001.

; DUTRA, A.; LYRIO, M. V. L. A gestão das operações na Secretaria Estadual de Desenvolvimento Regional da Grande Florianópolis: ênfase na sustentabilidade em um modelo de Avaliação de Desempenho. In: SIMPOI, 9., 2006, São Paulo. Anais... São Paulo: FGV - EAESP, 2006. CD-ROM.

; GIFFHORN, E.; ENSSLIN, S. R.; PETRI, S. M.; VIANNA, W. B. Avaliação do desempenho de empresas terceirizadas com o uso da metodologia multicritério de apoio à decisão - construtivista. Pesquisa Operacional, Rio de Janeiro, v. 30, n. 1, p. 125-152, jan./abr. 2010.

FINEP - Financiadora de Estudos e Projetos. Disponível em: 〈http://www.finep.gov.br〉. Acesso em: 11 dez. 2010.

HART, S.; HULTINK, E. J.; COMMANDEUR, H. R. Industrial companies' evaluation criteria in new product development gates. Journal of Product Innovation Management, v. 20, n.1, p. 22-36, January 2003.

cross ref

JACOB, W. F.; KWAK, Y. H. In search of innovative techniques to evaluate pharmaceutical R\&D projects. Technovation, v. 23, n.4, p. 291-296, April 2003.

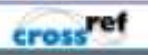

KEENEY. R. L. Value focused-thinking: a path to creative decision-making. Cambridge: Harvard Univ. Press, 1992.

LIAO, Z. Q. International R\&D project evaluation by multinational corporations in the electronics and IT industry of Singapore. R \& D Management, v. 31, n. 3, p. 299-307, July 2001.

cross ref

LIGINLAL, D.; RAM, S; DUCKSTEIN, L. Fuzzy measure theoretical approach to screening product innovations. IEEE Transactions on Systems Man and Cybernetics Part a-Systems and Humans, v.36, n.3, p.577-591, May 2006.

LOCH, C. H. et al. Selecting R\&D projects at BMW: A case study of adopting mathematical programming models. IEEE Transactions on Engineering Management, v. 48, n. 1, p. 70-80, February 2001.

cross ref

MARCHEWKA, J. T. Information technology project management, providing measurable organizational value. Jonh Wiley and Sons. 2003.

MAVROTAS, G.; DIAKOULAKI, D.; KOURENTZIS, A. Selection among ranked projects under segmentation, policy and logical constraints. European Journal of Operational Research, v. 187, n. 1, p. 177-192, May 2008.

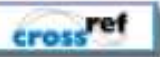


OZER, M. Process implications of the use of the Internet in new product development: a conceptual analysis. Industrial Marketing Management, v. 32, n. 6, p. 517-530, August 2003.

cross ref

PEREITA, J. M.; KRUGLIANSKA, I. Lei de Inovação Tecnológica: Instrumento efetivo de incentivo a inovação e a pesquisa no Brasil? Revista Gestão Industrial, Paraná, v. 02, n.02, p. 98-114, 2006.

cross ref

RICHARDSON, R. J. Pesquisa social: métodos e técnicas. 3. ed. ver. amp. São Paulo: Atlas, 2008.

ROY, B. Decision-aid and decision making. in: BANA E COSTA (ed.) Readings in Multiple Criteria Decision Aid, Berlin: Springer, p. 17-35, 1990.

SOARES, D.; VALLE, R.; BALDAM, R.; RAGONEZI, T. Inovação de Processos - Um estudo comparativo sobre sua implementação. Revista Gestão Industrial, Paraná, v. 02, n.04, p. 51-62, 2006.

cross ref

YANOMINI, F. M.; GONÇALVES, F. de O. Financiamento do crescimento da indústria brasileira: seriam as fontes adequadas aos regimes tecnológicos setoriais? Revista Brasileira de Inovação, Rio de Janeiro, v. 9, n. 1, p. 69-92, jan./jun. 2010.

YIN, R. K. Estudo de caso: planejamento e métodos. 3. ed. Porto Alegre: Bookman, 2005.

\section{Dados dos Autores:}

\section{Nome Completo: Diane Rossi Maximiano Reina}

Filiação Institucional: Universidade Federal de Santa Catarina (UFSC)

Departamento: Mestranda do Programa de Pós-graduação em contabilidade.

Função ou Cargo ocupado: Professora do Curso de Graduação em Ciências Contábeis.

Endereço: Rua Julio D’acia Barreto, 500- Fundos, Saco dos Limões - Florianópolis - Santa

Catarina - Brasil - CEP: 88.040-520.

Telefone para contato: (48) 9607-6531.

e-mail: dianereina@hotmail.com

\section{Nome Completo: Sandra Rolim Ensslin}

Filiação Institucional: Universidade Federal de Santa Catarina (UFSC)

Departamento: Programa de pós-graduação em Contabilidade e Engenharia da Produção

Função ou Cargo ocupado: Professora.

Endereço: Rua Itararé, 41, Parque São Jorge, Itacorubi - Florianópolis - Santa Catarina - Brasil -

CEP: $88.034-470$

Telefone para contato: (48) 3721-9383

e-mail: sensslin@gmail.com

\section{Nome Completo: Leonardo Ensslin}

Filiação Institucional: Universidade Federal de Santa Catarina (UFSC)

Depertamento: Programa de pós-graduação em Contabilidade e Engenharia da Produção 
Função ou Cargo ocupado: Professor.

Endereço: Rua Itararé, 41, Parque São Jorge, Itacorubi - Florianópolis - Santa Catarina - Brasil CEP: $88.034-470$

Telefone para contato: (48) 3721-2724

e-mail: leonardoensslin@gmail.com

Nome Completo: Donizete Reina

Filiação Institucional: Universidade Federal de Santa Catarina (UFSC)

Departamento: Mestre em Contabilidade

Função ou Cargo ocupado: Professor do Curso de Graduação em Ciências Contábeis.

Endereço: Rua Frederico Veras, 115- apto 504, Pantanal - Florianópolis - Santa Catarina - Brasil CEP: 88.040-200

Telefone para contato: (48) 3238-5617

e-mail: dreina2@hotmail.com

Recebido em: 19/10/2011

Aceito em: 27/07/2012 